\title{
"Model Predictive Current Control of a Slow Battery Charger for Electric Mobility Applications"
}

CONTROLO Portuguese Conference on Automatic Control, Guimarães - Portugal, Sept. 2016.

https://link.springer.com/chapter/10.1007/978-3-319-43671-5_54

ISBN: 978-3-319-43670-8

DOI 10.1007/978-3-319-43671-5_54

This material is posted here according with:

"The Author may self-archive an author-created version of his/her Contribution on his/her own website and/or in his/her institutional repository, including his/her final version. He/she may also deposit this version on his/her funder's or funder's designated repository at the funder's request or as a result of a legal obligation, provided it is not made publicly available until 12 months after official publication."

(C) 2014 SPRINGER 


\title{
Model Predictive Current Control of a Slow Battery Charger for Electric Mobility Applications
}

\author{
Delfim Pedrosa ${ }^{1}$, Ricardo Gomes ${ }^{1}$, Vitor Monteiro ${ }^{1}$, José A. Afonso ${ }^{2}$, João L. Afonso ${ }^{1}$ \\ ${ }^{1}$ Centro ALGORITMI, University of Minho, 4804-533, Guimarães, Portugal \\ \{delfim.pedrosa, ricardo.gomes, vitor.monteiro, \\ joao.1.afonso\} ealgoritmi.uminho.pt \\ ${ }^{2}$ CMEMS-UMinho R\&D Center, University of Minho, 4804-533, Guimarães, Portugal \\ jose.afonso@dei.uminho.pt
}

\begin{abstract}
This paper presents a model predictive current control applied to a slow electric vehicle (EV) battery charger. Taking into account the similarities between the power converters inside the EV, it is possible to combine the battery charger and the motor driver in a single integrated converter, thus reducing the weight and volume of the proposed solution, and also contributing to reduce the final price of the EV. Due to the bidirectional power flow capability of the integrated power converter, when working as a slow EV battery charger it can operate in grid-to-vehicle $(\mathrm{G} 2 \mathrm{~V})$ mode and in vehicle-to-grid (V2G) mode, contributing to make EVs an important assets in the future smart grids. The integrated power converter working as battery charger operates with sinusoidal current and unitary power factor, contributing to improve the power quality of the electrical grid. This paper provides simulation and experimental results that validate the model predictive control algorithm applied to the proposed integrated power converter working as slow EV battery charger.
\end{abstract}

Keywords: Electric Vehicles, Slow Battery Charger, Model Predictive Current Control, G2V - Grid-to-Vehicle, V2G - Vehicle-to-Grid.

\section{Introduction}

Nowadays, electric vehicles (EVs) are emerging as the most sustainable alternative to support the expected number of vehicles in circulation around the world, as well as to reduce the impact of the transportation sector on the environment. Typically, an EV has a motor drive system and an on-board battery charger that allows charging its battery pack almost anywhere, as long as there is an electrical outlet available [1]. Taking into account the similarities between the EV motor drive and the EV battery charger, it is possible the unification in a single converter, allowing to optimize the size and weight of the power components inside the EV [2]. Moreover, the bidirectional power flow capability of the converter offers some extra features for the EV operation into the power grid. Besides the grid-to-vehicle (G2V) operation mode, where the EV batteries are charged from the power grid, the EV battery charger can also be used to return part 
of the energy stored in the batteries back to the power grid. This operation mode is identified in the literature as vehicle-to-grid (V2G). Both G2V and V2G operation modes contribute to the development and expansion of technologies to integrate the EV into the smart grids $[3,4]$. In order to mitigate power quality problems, the EV battery charger should operate with unitary power factor and sinusoidal currents, i.e., with low total harmonic distortion [2], [5].

Fig. 1 presents the topology of the integrated power converter that is used as EV motor driver or as slow EV battery charger. As it can be seen, this topology can be used to perform the EV motor driver or the slow EV battery charging, since these operations do not happen simultaneously. From Fig. 1, it is possible to observe that the EV battery charging process is performed from the power grid using only two legs of the three-phase voltage source converter. It is important to note that the presented topology is compatible with any type of EV motor, nevertheless, an extra relay is necessary to disconnect the EV motor during the EV battery charging process. This converter can also be used as fast EV battery charger, however, this paper only focus in the slow EV battery charging process.

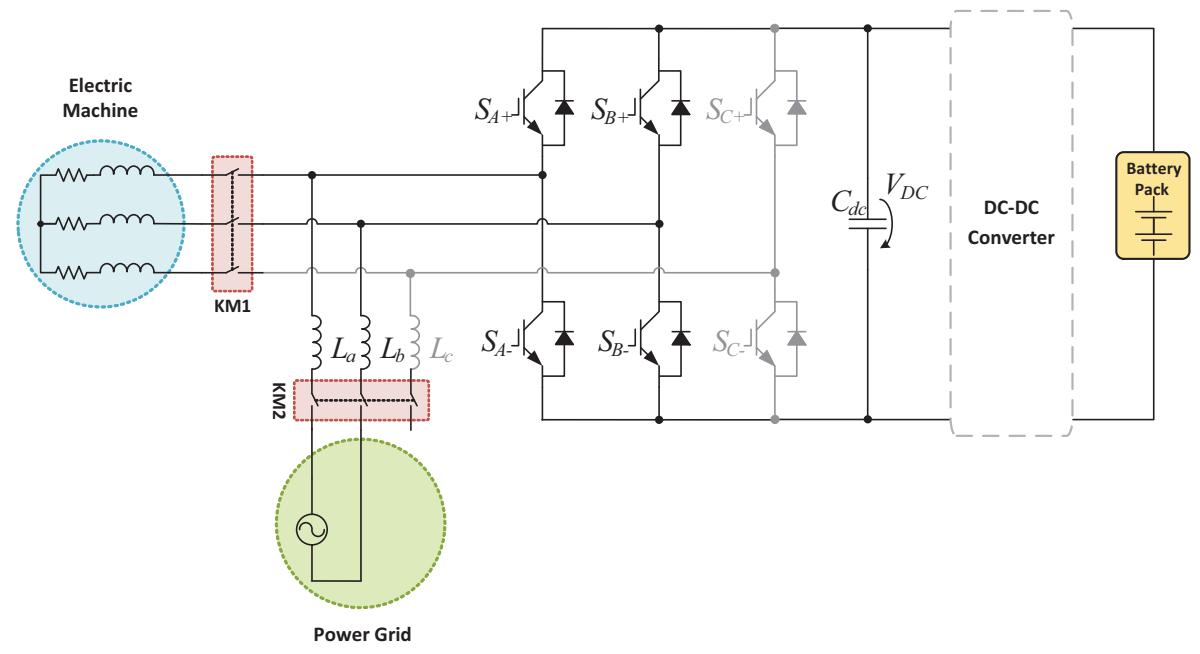

Fig. 1. Topology of the integrated power converter used both as EV motor driver and as slow EV battery charger.

\section{Predictive Current Control}

Fig. 2 describes the control algorithm to perform the slow EV battery charging process. Analyzing the voltages between the power grid and the AC-DC converter, it can be established that:

$$
v_{s}(t)=v_{R}(t)+v_{L}(t)+v_{i n}(t)=R_{s} i_{s}(t)+L_{s} \frac{d i_{s}(t)}{d t}+v_{i n}(t)
$$


where, $v_{s}(t)$ is the power grid voltage, $v_{R}(t)$ is the voltage across the internal resistance of the inductor, $v_{L}(t)$ is the voltage across the inductor, $v_{i n}(t)$ is the input voltage in converter, $R_{s}(t)$ is the internal resistance of the inductor, and $i_{s}(t)$ is the grid current. From equation (1), the derivative can be described by:

$$
\frac{d i_{s}(t)}{d t}=\frac{1}{L_{s}}\left[v_{s}(t)-R_{s} i_{s}(t)-v_{\text {in }}(t)\right]
$$

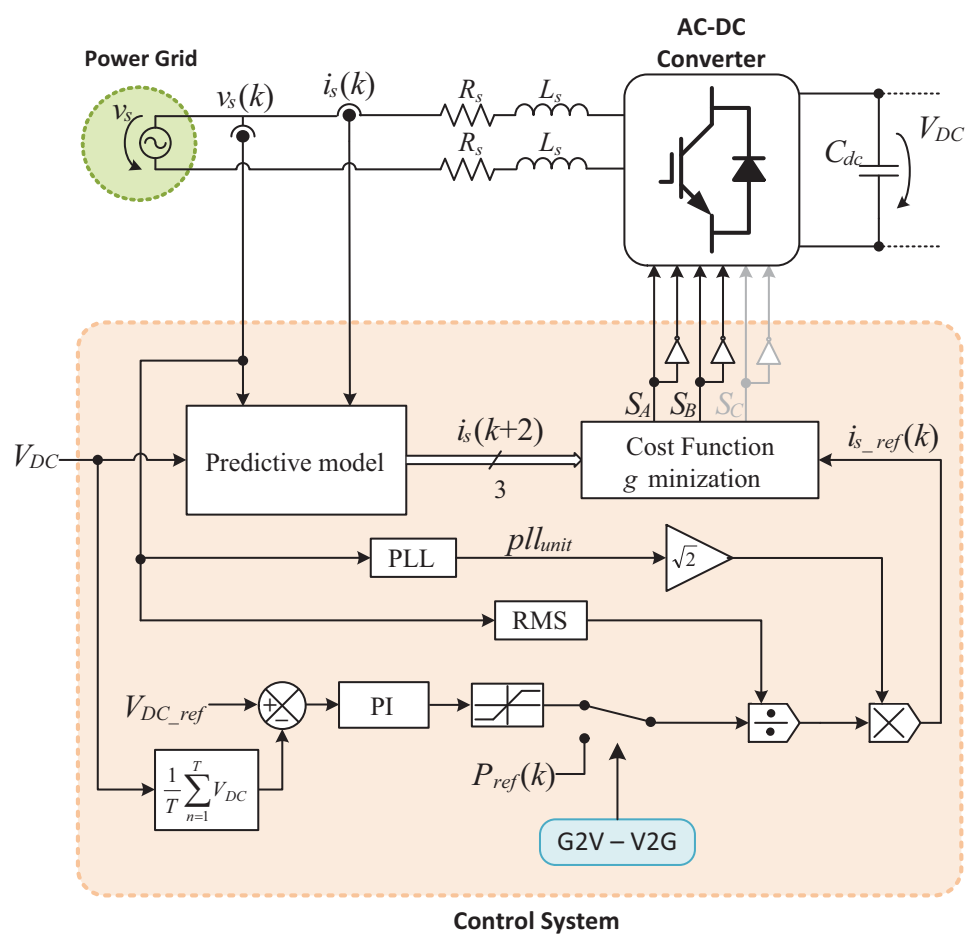

Fig. 2. Block diagram of the model predictive current control for the slow EV battery charger.

Applying the forward Euler approximation to the derivative of the grid current results in:

$$
\frac{d i_{s}(t)}{d t} \cong \frac{i_{s}(k+1)-i_{s}(k)}{T_{s}}
$$

where, the predicted input current is established by:

$$
i_{s}(k+1)=\left(1-\frac{R_{s} T_{s}}{L_{s}}\right) i_{s}(k)+\frac{T_{s}}{L_{s}}\left[v_{s}(k)-v_{\text {in }}(k)\right]
$$

Using a high sampling frequency, the voltage in the instant $(k+1)$ can be approximated by the voltage in the instant $(k)$, according to:

$$
v_{s}(k+1) \approx v_{s}(k)
$$


Taking into account that it is not possible to measure the control variables, predict the future values and apply the control during the same sampling period, the measured variables in the instant $(k)$ will result in changes in the instant $(k+2)$, causing a twostep-ahead prediction $[6,7]$. The output of the prediction can only be applied at the next sample $(k+1)$. Thus, it is necessary to predict the current value at the sample $(k+2)$, which is obtained by time shifting equation (4) one step forward, resulting in (6).

$$
i_{s}(k+2)=\left(1-\frac{R_{s} T_{s}}{L_{s}}\right) i_{s}(k+1)+\frac{T_{s}}{L_{s}}\left[v_{s}(k+1)-v_{i n}(k+1)\right]
$$

First, it is calculated $i_{s}(k+1)$ using equation (4), since the voltage and current measured were obtained as consequence of the switching state desired in the previous sampling time. In the next steps the predicted current is obtained with (6). Taking into account that the EV battery charger is connected to a single-phase system, it is used a cost function widely used in $[8,9]$, which is described by:

$$
g=\left|i_{s_{-} r e f}(k+2)-i_{s}(k+2)\right|
$$

From [4], where it is proposed a bidirectional single-phase battery charger for an $\mathrm{EV}$, the reference current during the $\mathrm{G} 2 \mathrm{~V}$ operation mode is generated according to Fig. 3 (a). In order to avoid the harmonic content of the power grid voltage it is used a phase-locked loop (PLL) algorithm, which is synchronized with the fundamental component of the power grid voltage. The RMS value of the grid current reference $\left(I_{S}\right.$ ref $)$ is obtained from a PI controller, which is used to maintain the DC-bus voltage regulated, divided by the RMS value of the power grid voltage. The RMS value of the grid current reference $\left(I_{S_{-}} r f\right)$ is then multiplied by the output signal of the PLL in order to obtain the instantaneous value of the grid current reference in phase with the power grid voltage. On the other hand, during the $\mathrm{V} 2 \mathrm{G}$ operation mode the grid current reference is in phase opposition with the power grid voltage. This is obtained using the same PI controller, but multiplying by minus one the output signal of the PLL. The block diagram that allows obtain the grid current reference during the V2G operation mode is shown in Fig. 3 (b).

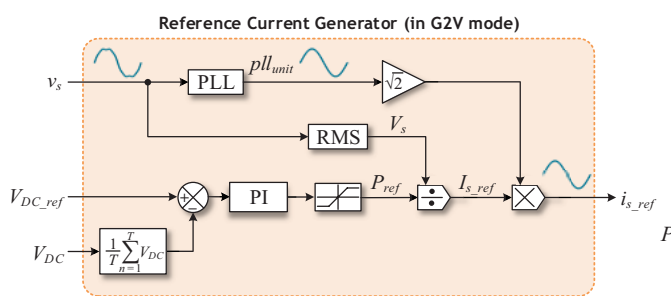

(a)

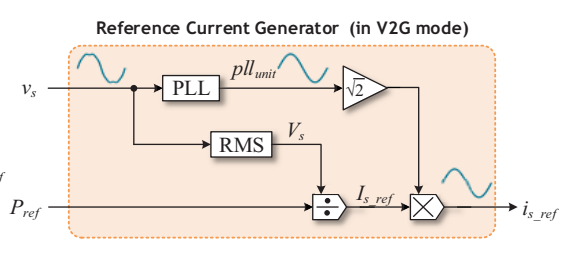

(b)

Fig. 3. Block diagram to obtain the grid current reference during: (a) G2V operation mode; (b) V2G operation mode.

As aforementioned, in order to obtain the grid current reference it is necessary to use a PLL algorithm. In this paper it was chosen to use the PLL algorithm shown in Fig. 4. 
This PLL algorithm results from the adaptation of the enhanced PLL (ePLL) presented in $[10,11]$.

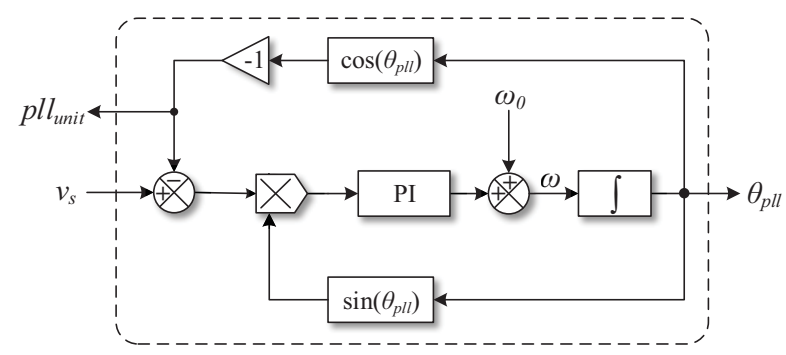

Fig. 4. Phase-locked loop algorithm used to synchronize the slow EV battery charger with the power grid voltage.

\section{Simulations Results}

This item presents the main simulation results obtained to validate the control algorithm of the slow EV battery charger. The simulation model was implemented as close as possible of the real implementation. With the realization of the simulations, it was possible to reduce time and financial resources during the implementation of the laboratorial prototype. The simulation results were obtained with the simulation software PSIM, v9.0. The simulations of the slow EV battery charger were performed for both G2V and V2G operations modes.

\subsection{Phase-Locked Loop Algorithm}

The performance of the PLL algorithm has high influence on the obtained results. Thus, the first simulations were done with the purpose of evaluating the performance of the PLL algorithm and tuning its parameters. In order to approximate the simulation model to the real implementation, it was considered a power grid voltage $\left(v_{s}\right)$ with harmonic content (third order harmonic with $15 \%$ of the amplitude of the fundamental component and seventh order harmonic with $10 \%$ of the amplitude of the fundamental component).

Fig. 5 (a) shows the output signal of the PLL algorithm ( pll $_{\text {unit }}$ ) in comparison with the power grid voltage $\left(v_{s}\right)$. In this case, the measured THD of the power grid voltage $\left(v_{s}\right)$ was $10.99 \%$, while the measured THD of the PLL ( $p l l_{\text {unit }}$ ) was $0.42 \%$, demonstrating the good performance of the PLL algorithm.

Fig. 5 (b) presents the harmonic spectrum of the power grid voltage $\left(v_{s}\right)$ in comparison with the PLL $\left(p l l_{\text {unit }}\right)$. The obtained results show that the PLL algorithm was capable to synchronize with the fundamental component of the power grid voltage, even considering a power grid voltage with a THD of $10.99 \%$.

It is important to note that the obtained results with the PLL algorithm can be improved by readjusting the gains of the PI controller. 


\subsection{Grid-to-Vehicle Operation Mode}

This item presents the simulation results during the G2V operation mode. For such purpose it was established a reference voltage for the DC-bus $\left(V_{D C_{-} r e f}\right)$ of $110 \mathrm{~V}$.

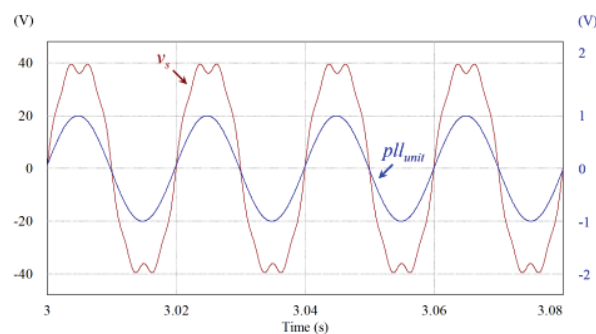

(a)

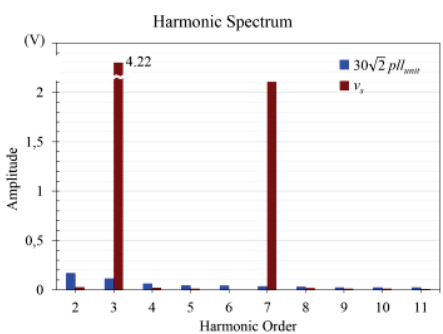

(b)

Fig. 5. Simulations of the PLL algorithm: (a) Power grid voltage $\left(v_{s}\right)$ and output signal of the PLL ( $\left.p l l_{\text {unit }}\right)$; (b) Detail of the harmonic spectrum of the power grid voltage $\left(v_{s}\right)$ and output signal of the PLL (pll unit).

The obtained waveforms of the power grid voltage $\left(v_{s}\right)$ and grid current $\left(i_{s}\right)$ are presented in Fig. 6 (a). The measured RMS value of the grid current $\left(i_{s}\right)$ was $7.14 \mathrm{~A}$, the measured THD was $9.57 \%$, and the measured total power factor was 0.99 . The detailed harmonic spectrum of the grid current $\left(i_{s}\right)$, in comparison with the limits established by the standard IEC 61000-3-2, is presented in Fig. 6 (b).

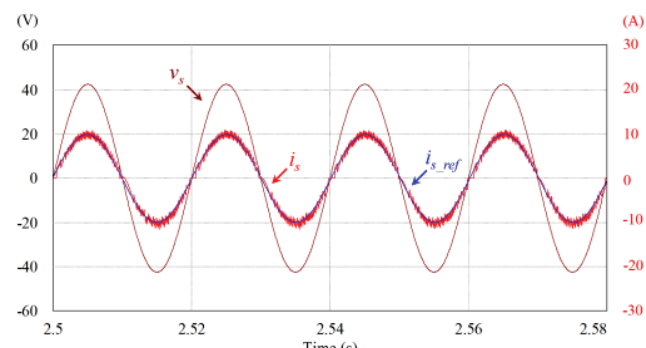

(a)

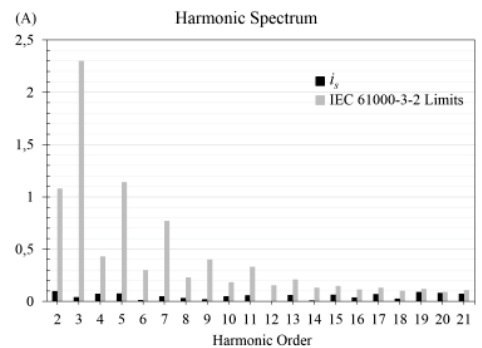

(b)

Fig. 6. Simulation results during the G2V operation mode: (a) Power grid voltage $\left(v_{s}\right)$, grid current $\left(i_{s}\right)$, and grid current reference $\left(i_{s_{-}} r e f\right)$; (b) Detail of the harmonic spectrum of the grid current $\left(i_{s}\right)$ in comparison with the limits established by the standard IEC 61000-3-2.

Fig. 7 shows the DC-bus voltage. As it can be seen, the DC-bus voltage is centered in its reference $(110 \mathrm{~V})$ with a voltage ripple of $9.80 \%$. 


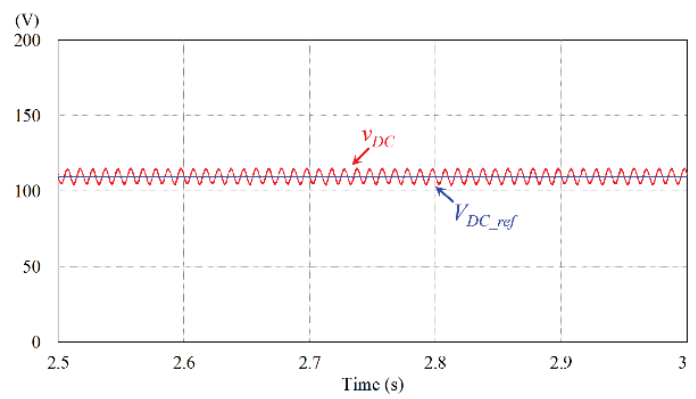

Fig. 7. Simulation results of the DC-bus voltage $\left(v_{D C}\right)$ and its reference $\left(V_{D C}\right.$ ref $)$ during G2V operation mode.

\subsection{Vehicle-to-Grid Operation Mode}

This item presents the simulation results during the V2G operation mode. For this operation mode it was established an operation power of $0.2 \mathrm{~kW}$. The obtained waveforms of the power grid voltage $\left(v_{s}\right)$ and grid current $\left(i_{s}\right)$ are shown in Fig. 8 (a). The grid current $\left(i_{s}\right)$ has a RMS value of $6.58 \mathrm{~A}$ and a THD value of $17.46 \%$. The harmonic spectrum of the grid current is shown in Fig. 8 (b).

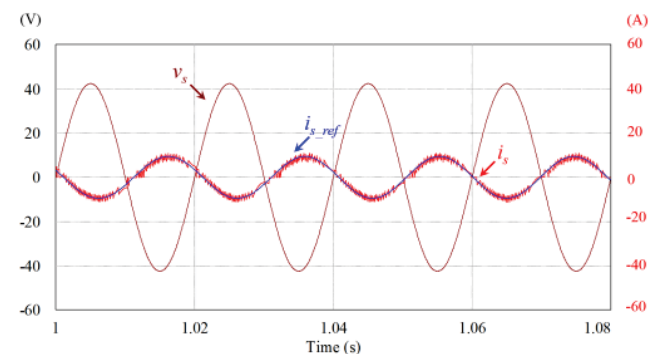

(a)

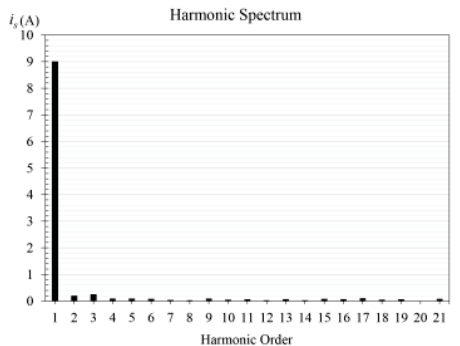

(b)

Fig. 8. Simulation results during the V2G operation mode: (a) Power grid voltage $\left(v_{s}\right)$, grid current $\left(i_{s}\right)$ and grid current reference $\left(i_{s_{-}} r f\right)$; (b) Harmonic spectrum of the grid current $\left(i_{s}\right)$.

\section{$4 \quad$ System Implementation}

Fig. 9 shows the developed laboratorial prototype, which is divided in two fundamental parts: power converter and digital control. The power converter is a three-phase voltage source converter that is used as EV motor driver or as slow EV battery charger. Taking into account the operation as slow EV battery charger are only used two IGBTs legs, the inductors filters and the DC-bus capacitors.

The digital control system is composed by a digital signal controller (DSC), the current and voltage sensors, the signal conditioning circuits (one to adequate the signals from the sensors to the DSC and other to adapt the signals from the DSC to IGBTs drivers), and the IGBTs gate drivers. The power converter is isolated from the digital control system through the hall-effect sensors and the IGBTs gate drivers. 

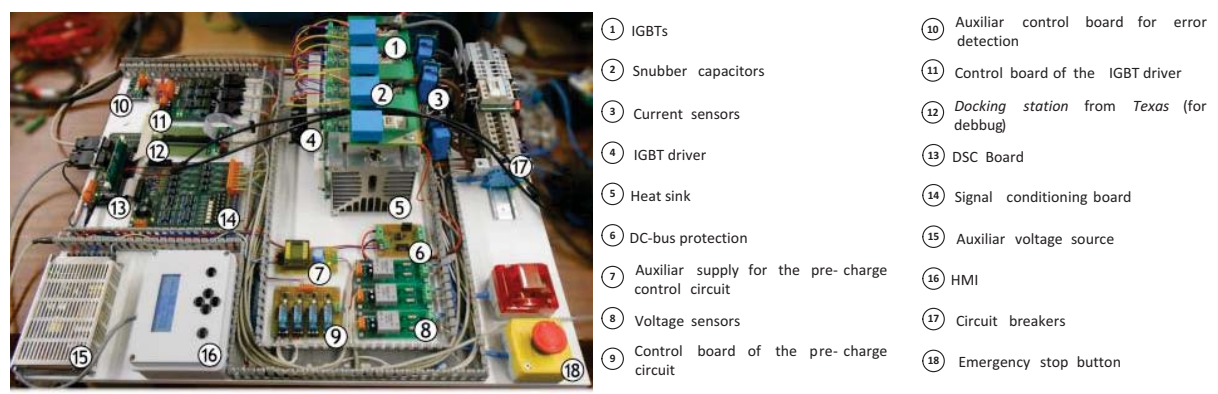

Fig. 9. Photograph and description of the developed laboratory prototype.

\section{$5 \quad$ Experimental Results}

This section presents the main experimental results obtained with the slow EV battery charger connected to the power grid with a nominal voltage of about $30 \mathrm{~V}$ RMS and a frequency of $50 \mathrm{~Hz}$. As aforementioned in the simulations section, the performance of the PLL system has high influence on the obtained results in both G2V and V2G operation modes.

The first step of the control system consists in evaluating the performance of the PLL algorithm. Fig. 10 shows the obtained results of the power grid voltage $\left(v_{s}\right)$ and the output signal of the PLL algorithm $\left(p l l_{\text {unit }}\right)$. As it can be seen, the PLL algorithm is capable of locking with the power grid voltage $\left(v_{s}\right)$.

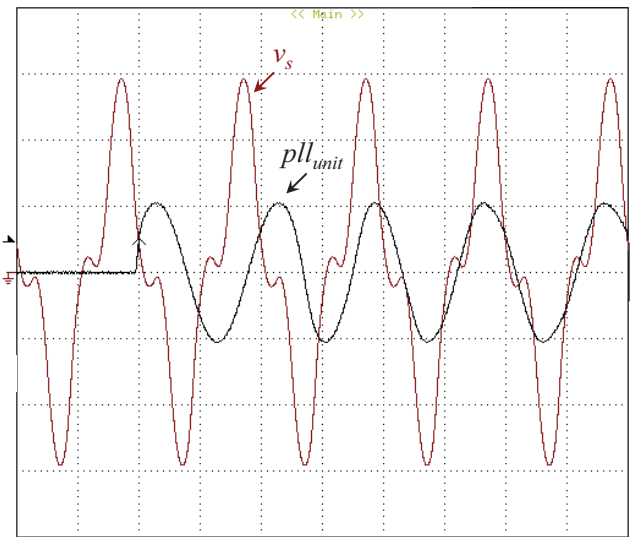

Fig. 10. Experimental results of the power grid voltage $\left(v_{s}: 20 \mathrm{~V} /\right.$ div $)$ and the output signal of the PLL algorithm (pllunit: $1 \mathrm{~V} /$ div) (Time: $10 \mathrm{~ms} /$ div).

After validating the PLL algorithm, the next step consists in regulating the DC-bus voltage $\left(V_{D C_{-} r e f}\right)$ to $110 \mathrm{~V}$. Fig. 11 (a) presents the obtained waveforms of the power grid voltage $\left(v_{s}\right)$, the output signal of the PLL $\left(p l l_{\text {unit }}\right)$, the grid current $\left(i_{s}\right)$ and its reference $\left(i_{s_{-} r e f}\right)$, as well as the DC-bus voltage $\left(V_{D C}\right)$. The harmonic spectrum and the RMS value of the grid current $\left(i_{s}\right)$ are shown in Fig. 11 (b). 


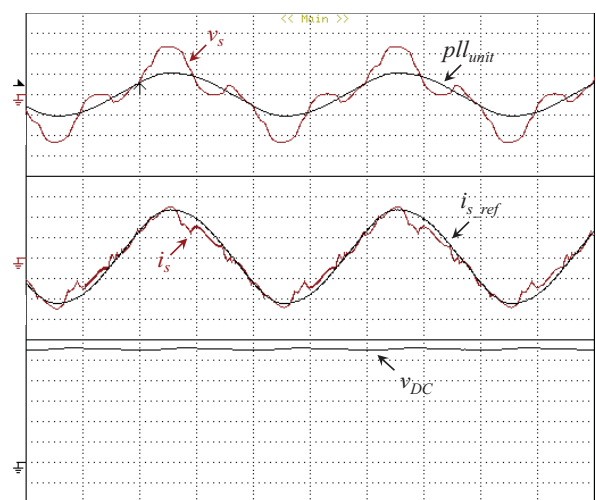

(a)

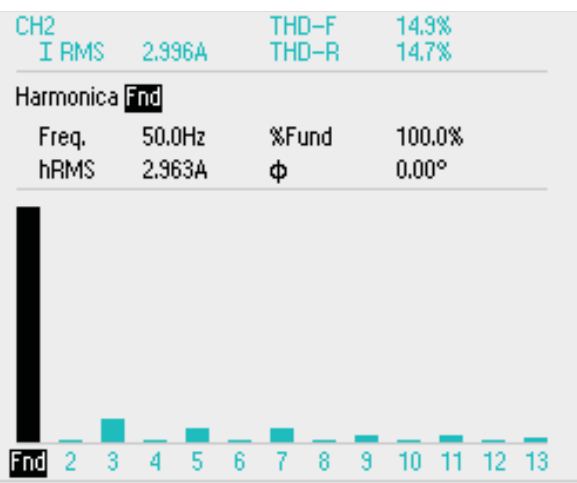

(b)

Fig. 11. Experimental results during the G2V operation mode: (a) Power grid voltage ( $\left.v_{s}: 20 \mathrm{~V} / \mathrm{div}\right)$, PLL output signal ( $\left.p l_{\text {unit }}: 1 \mathrm{~V} / \mathrm{div}\right)$, grid current $\left(i_{s}: 2 \mathrm{~A} / \mathrm{div}\right)$, grid current reference ( $i_{s_{-}}$ref. $\left.2 \mathrm{~A} / \mathrm{div}\right)$, DC-bus voltage ( $V_{D C}: 20 \mathrm{~V} / \mathrm{div}$ ) (Time: $5 \mathrm{~ms} / \mathrm{div}$ ); (b) Harmonic spectrum of the grid current $\left(i_{s}\right)$.

\section{Conclusions}

This paper presents a slow electric vehicle (EV) battery charger that uses a model predictive current control algorithm. This slow EV battery charger is part of an integrated power converter that can also be used as EV motor drive. This integrated converter contributes to optimize the weight and volume of the required power electronics when compared with the traditional solutions, where it is necessary to use a power converter to the EV motor driver and another to the slow EV battery charger.

Along the paper are presented the main simulation results about the synchronization of the phase-locked loop (PLL) with the power grid voltage, as well as the power grid voltage and the grid current during the grid-to-vehicle (G2V) and vehicle-to-grid (V2G) operation modes. The experimental results show the proper operation of the slow EV battery charger, which presents sinusoidal grid current with unitary power factor, contributing to mitigate power quality problems. The obtained results allow the validation of the model predictive current control applied to the slow EV battery charger, which is part of an integrated power converter used both as EV motor driver and as slow EV battery charger.

\section{Acknowledgements}

This work has been supported by COMPETE: POCI-01-0145-FEDER-007043 and FCT - Fundação para a Ciência e Tecnologia within the Project Scope: UID/CEC/00319/2013. Mr. Delfim Pedrosa was supported by the doctoral scholarship SFRH/BD/86628/2012 granted by the FCT agency. 


\section{References}

1. Haghbin, S., Lundmark, S., Carlson, O., Alakula, M.: A Combined Motor/Drive/Battery Charger Based on a Split-Windings PMSM. In: IEEE Vehicle Power and Propulsion Conference (VPPC), pp. 1-6. IEEE Press, Chicago (2011)

2. Haghbin, S., Khan, K., Lundmark, S., Alakula, M., Carlson, O., Leks, M., Wallmark, O.: Integrated Chargers for EV's and PHEV's: Examples and New Solutions. In XIX International Conference on Electrical Machines (ICEM), pp. 1-6. IEEE Press, Rome (2010)

3. Yilmaz, M., Krein, P.T.: Review of Battery Charger Topologies, Charging Power Levels, and Infrastructure for Plug-In Electric and Hybrid Vehicles. IEEE Transactions on Power Electronics, 28(5), 2151-2169 (2013)

4. Pinto, J. G., Monteiro, V., Goncalves, H., Exposto, B., Pedrosa, D., Couto, C., Afonso, J.L.: Bidirectional Battery Charger with Grid-to-Vehicle, Vehicle-to-Grid and Vehicle-to-Home Technologies. In 39th Annual Conference of the IEEE industrial Electronics Society (IECON 2013), pp. 5934-5939. IEEE Press, Vienna (2013)

5. Monteiro, V., Pedrosa, D., Exposto, B., Ferreira, J.C., Afonso, J.L.: Smart Charging System of the Electric Vehicle CEPIUM. In Annual Seminar on Automation, Industrial Electronics and Instrumentation (SAAEI'12), pp. 500-505 (2012)

6. Cortes, P., Rodriguez, J., Antoniewicz, P., Kazmierkowski, M.: Direct Power Control of an AFE Using Predictive Control. IEEE Transactions on Power Electronics, 23(5), 2516-2523 (2008)

7. Kouro, S., Cortes, P., Vargas, R., Ammann, U., Rodriguez, J.: Model Predictive Control - A Simple and Powerful Method to Control Power Converters. IEEE Transactions on Power Electronics, 56(6), 1826-1838 (2009)

8. Parvez, M., Mekhilef, S., Tan, N.M.L., Akagi, H.: Model predictive control of a bidirectional AC-DC converter for V2G and G2V applications in electric vehicle battery charger. In: IEEE Transportation Electrification Conference and Expo (ITEC), pp. 1-6. IEEE Press, Dearborn (2014)

9. Xingwu, Y., Hongchao, J., Wei, G.: Model predictive control of single phase grid-connected inverter. In: IEEE PES Asia-Pacific Power and Energy Engineering Conference (APPEEC), pp. 1-4. IEEE Press, Hong Kong (2014)

10. Karimi-Ghartemani, M., Iravani, M.R.: A new phase-locked loop (PLL) system. In: Proceedings of the 44th IEEE 2001 Midwest Symposium on Circuits and Systems, vol. 1, pp. 421-424. IEEE Press, Dayton (2001)

11. Karimi-Ghartemani, M., Iravani, M.R.: A nonlinear adaptive filter for online signal analysis in power systems: Applications. IEEE Transactions on Power Delivery, 17(2), 617-622 (2002) 